\title{
Hirschsprung Disease of the Adult Mimicked by Chronic Constipation or Vice Versa?
}

\author{
Juan Antonio Ramos ${ }^{\mathrm{a}, \mathrm{b}}$, Gary Stallings ${ }^{\mathrm{a}}$
}

\begin{abstract}
Hirschsprung disease is a rare congenital disorder characterized by a functional obstruction of the distal bowel due to aganglionic bowel segments with impaired motility. It is a rare condition in the adult, and usually mimicked by a long standing history of constipation, requiring great astuteness to diagnose. We present a case with all the clinical and radiologic characteristics of adult Hirschsprung disease, which had a final diagnosis of chronic constipation in a mentally impaired individual.
\end{abstract}

Keywords: Hirschsprung disease adults; Colonic aganglionosis; Constipation; Intestinal volvulus

\section{Introduction}

Hirschsprung disease (HD) is a congenital motor disorder of the gut, caused by failure of neural crest cells (precursors of enteric ganglion cells) to migrate completely during intestinal development to the Meissner (submucosal) and Auerbach (myenteric) plexuses. The resulting aganglionic segment of the colon fails to relax, causing a functional obstruction [1]. HD is usually a congenital disorder, occurring in approximately one in 5000 live births, with an overall male: female ratio of $3: 1$ to $4: 1$ [2], however, roughly $5 \%$ of HD cases are diagnosed in the adult population; it is frequently misdiagnosed as chronic constipation in these individuals $[3,4]$, and a common presentation is with volvulus of a colonic segment.

We present a case of chronic constipation with a clini-

\footnotetext{
Manuscript accepted for publication May 24, 2012

${ }^{a}$ Department of Internal Medicine, New York Medical College at Westchester Medical Center, 100 Woods rd Valhalla NY 10595 PMB 627, USA.

${ }^{\mathrm{b}}$ Corresponding author: Juan Antonio Ramos. Email: juan_ramos66@ hotmail.com
}

doi: $10.4021 / \mathrm{jmc} 731 \mathrm{w}$ cal history and radiologic findings [5] which mimicked Hirschsprung Disease diagnosed in the adult as described by case reports and series by others [3, 6-9].

\section{Case Report}

Our subject is a 65 years old male, skilled nursing facility resident, with a history of schizoaffective disorder and chronic constipation, with a recent admission to our institution one month prior with bowel obstruction secondary to sigmoid volvulus. The patient was surgically managed by subtotal colectomy with ileo-rectal anastomosis with an uneventful hospital course and was safely discharged. On present admission, one month later, he returned with three episodes of projectile vomiting of food and bilious material. Review of systems was positive for constipation, chronic in nature for our subject, as well as nausea. Abdominal X-ray showed distended bowel loops with a non-specific pattern, given the patient's history a CT scan of the abdomen with oral contrast was pursued (Fig. 1), which showed massive dilation of the remaining rectum and Ileal loops filled with impacted stool. He was managed conservatively with rectal tube decompression of the bowel as well as an aggressive bowel regimen. The patient's presentation and imagery prompted us to review the literature and begin a workup for possible adult presentation of Hirschsprung Disease. Anorectal manometry demonstrated an absent recto-anal inhibitory reflex. From these suggestive findings we proceeded to

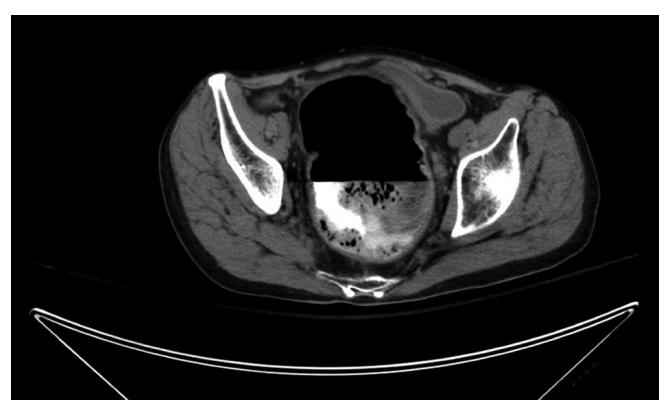

Figure 1. Severely dilated rectum with impacted stool and fluid level. 
perform a full thickness mucosal biopsy of the patient's remaining rectal mucosa, the gold standard diagnostic tool for HD [10], which failed to show aganglionosis of the remaining rectal mucosa, therefore discarding Hirschsprung of our differential diagnoses.

Our patient was treated symptomatically with an aggressive bowel regimen of stool softeners and bowel laxatives and he was again discharged safely to his skilled nursing facility.

\section{Discussion}

Hirschsprung disease is a rare condition resulting in aganglionosis of the Meissner (submucosal) and Auerbach (myenteric) plexuses of the gut. In the majority of patients, the disorder affects a short segment of the distal colon, with a transition zone in the rectosigmoid colon. This condition was first described by Harald Hirschsprung in 1886 [11]. The majority of patients with HD are diagnosed in the neonatal period [1], and though adult onset HD was thought to be rare, Hirschsprung himself had suggested as early as 1900, that the disease was not confined to children and several cases of adult HD have been reported since then [12]. About 5\% of patients with less severe disease may not be diagnosed until early adulthood, most of them between the second and third decade of life, and are frequently misdiagnosed as chronic constipation [3, 4], these may not be truly diagnosed until an acute presentation with complications such as obstructive colitis, sigmoid volvulus or sub-acute obstructions [7]. Several cases have been diagnosed after presenting with a volvulus of the gut $[6,8,9]$, likely due to an aganglionic segment of gut below the sigmoid colon and a freely mobile mesosigmoid [13].

The above described clinical vignette in addition to manifest radiologic imagery similar to that described in the literature [5] prompted the authors to consider Hirschsprung disease in the adult setting for this patient whose most likely problem is rather chronic constipation. Constipation is the most common digestive complaint in the general population [14], with prevalence of 12 to 19 percent (average 15 percent) reported in most studies [15]. It is of utmost importance to recognize and treat chronic constipation in a timely and effective fashion to avoid complications such as the ones described above. This can be especially relevant in patients with pervasive developmental disorders, psychiatric disorders, the elderly, or any other type of patient population which may not be able to express appropriately nor act upon such a common gastrointestinal complaint.

\section{Conflict of Interest}

The authors state no conflict of interest for the crafting of this manuscript. No monetary sources were involved in the crafting the prior.

\section{References}

1. Kays DW. Surgical conditions of the neonatal intestinal tract. Clin Perinatol. 1996;23(2):353-375.

2. Kleinhaus S, Boley SJ, Sheran M, Sieber WK. Hirschsprung's disease -- a survey of the members of the Surgical Section of the American Academy of Pediatrics. J Pediatr Surg. 1979;14(5):588-597.

3. Chen F, Winston JH, 3rd, Jain SK, Frankel WL. Hirschsprung's disease in a young adult: report of a case and review of the literature. Ann Diagn Pathol. 2006;10(6):347-351.

4. Miyamoto M, Egami K, Maeda S, Ohkawa K, Tanaka N, Uchida E, Tajiri T. Hirschsprung's disease in adults: report of a case and review of the literature. J Nihon Med Sch. 2005;72(2):113-120.

5. Fortea-Sanchis C, Martinez-Ramos D, Rivadulla-Serrano I, Daroca-Jose JM, Paiva-Coronel G, SalvadorSanchis JL. Hirschprung's disease in adults. Rev Esp Enferm Dig. 2011;103(3):150-151.

6. Alagumuthu M JS, Kadambari D. Hirschsprung's disease in adults presenting as sigmoid volvulus: a report of three cases. Tropical Gastroenterology 2011;4(32):343-5.

7. Bakari AA, Gali BM, Ibrahim AG, Nggada HA, Ali N, Dogo D, Abubakar AM. Congenital aganglionic megacolon in Nigerian adults: two case reports and review of the literature. Niger J Clin Pract. 2011;14(2):249-252.

8. Ghaemi M, Bahar MM, Motie MR, Hiradfar M, Soltani E, Saremi E. Late presentation of Hirschsprung's disease as sigmoid colon volvulus: report of four cases and review of the literature. Colorectal Dis. 2010;12(7):704-705.

9. Tan FL, Tan YM, Heah SM, Seow-Choen F. Adult Hirschsprung's disease presenting as sigmoid volvulus: a case report and review of literature. Tech Coloproctol. 2006;10(3):245-248.

10. De Lorijn F, Reitsma JB, Voskuijl WP, Aronson DC, Ten Kate FJ, Smets AM, Taminiau JA, et al. Diagnosis of Hirschsprung's disease: a prospective, comparative accuracy study of common tests. J Pediatr. 2005;146(6):787-792.

11. Hirschsprung H. Stuhltragheit Neugeborener infolge von Dilatation und Hypertrophie des Colons. Jahrb Kinderheilkd 1887;27:1-42.

12. Lesser PB, El-Nahas AM, Lukl P, Andrews P, Schuler JG, Filtzer HS. Adult-onset Hirschsprung's disease. JAMA. 1979;242(8):747-748.

13. Sarioglu A, Tanyel FC, Buyukpamukcu N, Hicsonmez A. Colonic volvulus: a rare presentation of Hirschsprung's disease. J Pediatr Surg. 1997;32(1):117-118.

14. Stewart WF, Liberman JN, Sandler RS, Woods MS, 
Stemhagen A, Chee E, Lipton RB, et al. Epidemiology of constipation (EPOC) study in the United States: relation of clinical subtypes to sociodemographic features. Am J Gastroenterol. 1999;94(12):3530-3540.
15. Suares NC, Ford AC. Prevalence of, and risk factors for, chronic idiopathic constipation in the community: systematic review and meta-analysis. Am J Gastroenterol. 2011;106(9):1582-1591; quiz 1581, 1592. 